\title{
Annual Cycle of Zooplankton Biomass, Abundance and Species Composition in the Neritic Area of the Balearic Sea, Western Mediterranean
}

\author{
M$^{\mathrm{a} L u z}$ Fernández de Puelles ${ }^{1, *}$, David Grás ${ }^{2}$ \& Santiago Hernández-León ${ }^{3}$ \\ ${ }^{1}$ Oceanographic Center of Baleares, Spanish Institute of Oceanography, P.O.Box. 291, 07080 \\ Palma de Mallorca, Spain. \\ ${ }^{2}$ Institute of Litoral Ecology, 03560 El Campello, Alicante, Spain. \\ ${ }^{3}$ Biological Oceanography Laboratory, Facultad de Ciencias del Mar, Universidad de Las \\ Palmas de G.C., Campus Universitario de Tafira, 35017 Las Palmas de GC, Canary Islands, \\ Spain.
}

With 6 figures and 2 tables

Keywords: Annual cycle, zooplankton, biomass, copepod species, environmental variables, Balearic Sea.

\begin{abstract}
Seasonal changes in zooplankton biomass, abundance and species composition were studied at a neritic station in the Balearic Sea between April 1993 and May 1994. Sampling was carried out every 10 days in a zone influenced by the main current circulating through the Mallorca channel. Three main peaks of zooplankton biomass and abundance were observed: (1) at the beginning of summer when the thermocline developed, (2) in autumn when the thermocline broke down, and (3) in early spring. The smaller zooplankton fraction $(100-250 \mu \mathrm{m})$ comprised on average $32 \%$ of the total biomass and $73 \%$ of total abundance. Copepods were the predominant group (64\% of the total abundance) with Clausocalanus, Oithona and Paracalanus being the most abundant genera. Paracalanus parvus, Clausocalanus furcatus, Acartia clausi, Oithona plumifera, Temora stylifera, Centropages typicus and Oncaea mediterranea were found to be the most important species in the area. Other abundant groups were cladocerans $(15 \%)$ and meroplankton larvae $(12 \%)$, both of which were particularly numerous during the stratified period. The copepod community was characterized by the abovecited perennial species, which were abundant during the cycle studied. However, the influence of the hydrological conditions of the Balearic Sea, such as the Atlantic water influx and the physical structure of the water column (stratification and mixing), promoted the observed variability in zooplankton as well as the appearance of characteristic species during the annual cycle.
\end{abstract}

\footnotetext{
* Author to whom correspondence should be addressed. E-mail: mluz.fernandez@ba.ieo.es
} 